\title{
Interruption of the Arterial Inferior Alveolar Flow and Its Effects on Mandibular Collateral Circulation and Dental Tissues
}

\author{
W. A. CASTELLI, C. E. NASJLETI, and R. DÍAZ-PEREZ \\ University of Michigan Medical and Dental School, Department of Anatomy, \\ Veterans Administration Hospital, Ann Arbor, Michigan 48104, USA and \\ Annapolis Hospital, Detroit, Michigan
}

The interruption of circulation through the inferior alveolar artery was followed by the establishment of a fast retrograde blood flow through the vessel. The mental artery and the mandibular branch of the sublingual artery were the main vessels to contribute to that flow. No histopathologic changes were found in the experimental hemimandibles; however, temporary regressive changes were found in the dental pulps of molars.

As has been stated by Skopakof, 1 the mental branch of the inferior alveolar artery and the mandibular branch of the sublingual artery are the main collateral vessels that supply the mandibular body when circulation through the inferior alveolar artery has been interrupted. These vessels must experience a compensatory process of growth to meet the nutrient demands of the mandibular body. However, the kinetics and physiologic mechanisms involved in the growth of the vessels as a consequence of the inferior alveolar artery obliteration have not been discussed in detail. It is also probable that the tissues located too distally to be supplied by the newly established retrograde circulation might have suffered some pathophysiologic changes as a result of disturbances in the hemodynamics of the local blood flow.

During surgical interventions on the mandible, the preservation of the inferior alveolar artery in the inferior alveolar canal has been considered important in providing

Received for publication August 15, 1974.

Accepted for publication January 9, 1975. good nutrition to the bone and in accelerating the healing process. ${ }^{2-4}$ On certain occasions, however, because of the nature and extent of the pathological process, the resection of the artery is an imminent fact. 5,6 Thus, preserving the main collateral circulation to the mandibular segments remaining after surgery is important for a successful mandibular reconstruction.

This investigation involves the study of the retrograde circulation established in the mandibular body after the inferior alveolar artery has been cauterized, the relative participation of the mental artery and the mandibular branch of the sublingual artery in originating and maintaining a retrograde blood flow, and the histopathologic changes that might occur in the mandibular body as a result of the interruption of circulation through the inferior alveolar artery.

\section{Materials and Methods}

The rhesus monkey (Macaca mulatta) was the animal chosen for this investigation because the morphology of the mandible, teeth, dental supporting tissues, and related vascular supply are similar to those of man. ${ }^{7-9}$

Anglogram study.-Nine young adult monkeys of both sexes and with permanent dentitions were used. General anesthesia was induced with pentobarbital sodium (Nembutala), $30 \mathrm{mg} / \mathrm{kg}$ of body weight.

The skin over the parotideomasseteric area was prepared routinely for surgery with adequate drapes to circumscribe the sur-

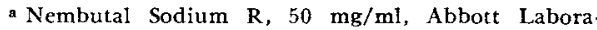
tories, Chicago, Ill.
} 


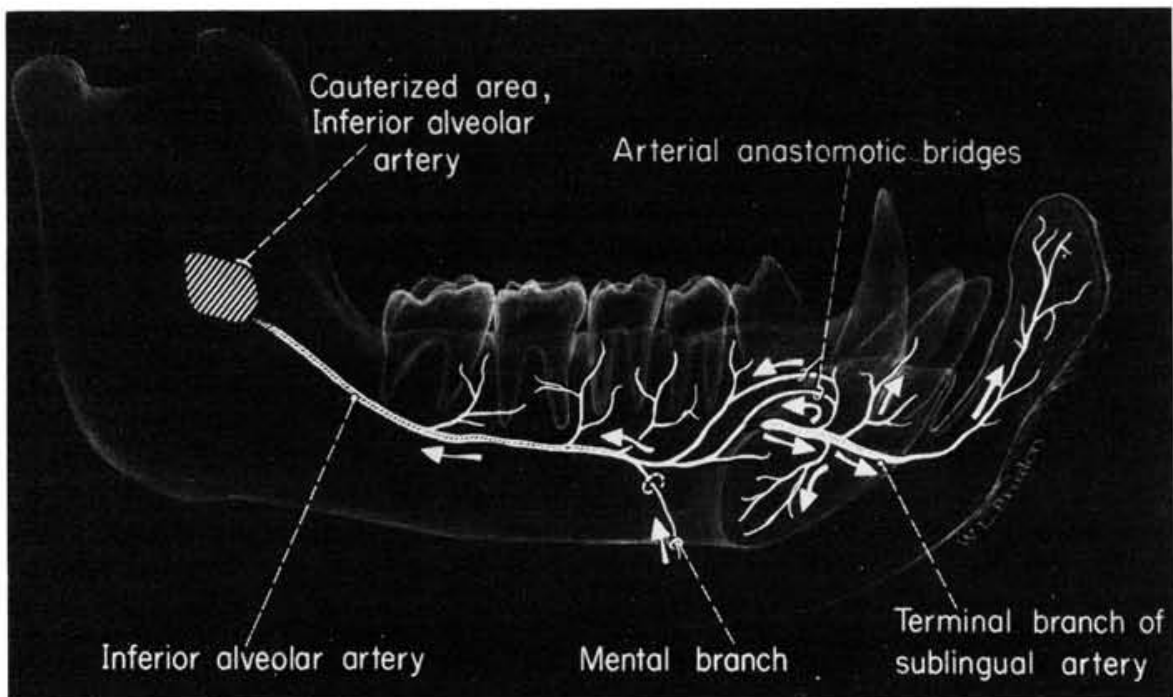

FIG 1.-Schematic representation of newly established retrograde circulation in mandible after inferior alveolar artery was cauterized.

gical field. A vertical cutaneous incision was made anterior to the auricle and inferior to the zygomatic arch to expose the parotid gland and masseter muscle covered by the parotideomasseteric fascia. After preparing suitable skin flaps, the fascia was dissected loose, the parotid gland packed posteriorly, and the masseter muscle incised vertically to reach the lateral surface of the ramus. The detachment of some masseter fibers from the surface of the ramus was necessary to create space for working with the surgical bur. The area of the mandibular ramus to be drilled to locate the inferior alveolar canal opening was determined by the point of in- tersection of two imaginary lines linking the coronoid process-mandibular angle, and the mandibular condyle-facial groove on the basilar border of the mandible. A careful drilling of the ramus followed until the inferior alveolar artery was identified. In most instances, during the arterial cauterization, the inferior alveolar nerve was damaged because of its close proximity to the artery in the inferior alveolar canal. Closing of the wound ended the surgical stage.

A daily intramuscular injection of penicillin-streptomycin $\left(\right.$ Combiotic $\left.^{b}\right)$ was given

b Combiotic, Pfizer, Inc., New York, NY.

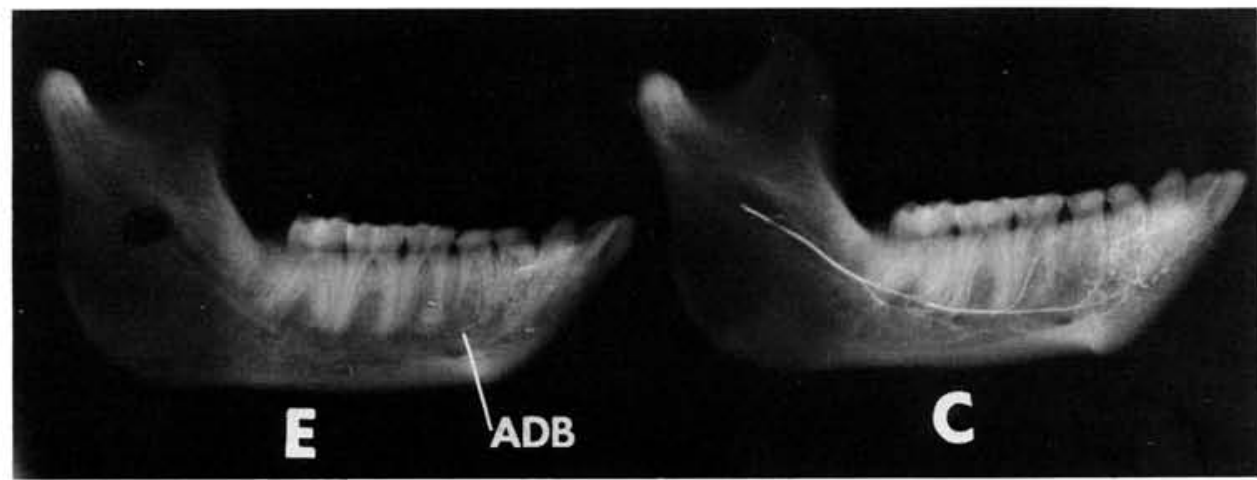

Fic 2.-Angiogram, one day after surgery. Tenuous alveolodental branches $(A D B)$ were noticeable in premolar area $(E)$. Control hemimandible $(C)$. 


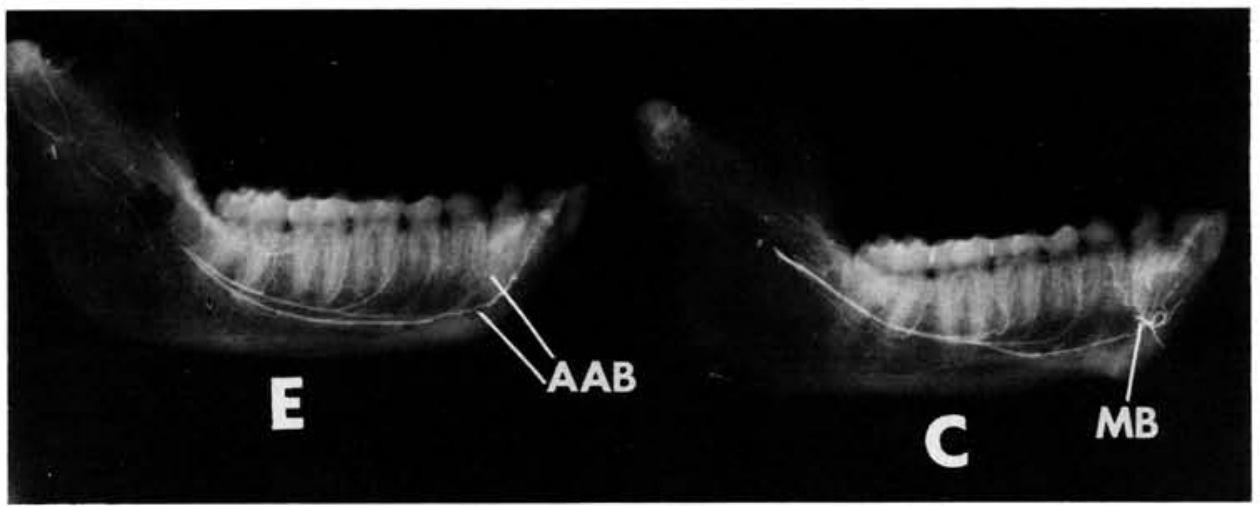

Fic 3.-Angiogram, two days after surgery. Full retrograde blood flow has been established on experimental side $(E)$. Arterial anastomotic bridges $(A A B)$ are also distinct structures. Mandibular branch $(M B)$.

for four days postoperatively to prevent secondary infections of the surgical wound, and the monkeys were given a soft diet for a week. The animals were killed at 1,2, 4,5 , and 12 days, and three, four, six, and nine weeks after surgery. Immediately after the monkeys were killed, both external carotid arteries were cannulated and a modified Schlessinger's radiopaque mass ${ }^{10}$ was perfused into the facial area for angiogram study. Pressure, averaging about $105 \mathrm{~mm}$ of mercury, was used for injecting the radiopaque material in both arteries, and this pressure was comparable to the systolic pressure in rhesus monkeys. ${ }^{11}$

All heads were removed and fixed in $10 \%$ buffered Formalin solution. The mandibles were extracted and cleaned and the periosteum was detached. Later, they were individually radiographed. The external diameter of the mental artery and that of the mandibular branch of the sublingual artery were measured on the specimens and radiographs using a dissecting microscope with a micrometer scale attached to it.

Histological study.-As a result of the angiogram evaluation, a histological study of the premolars and molars, periodontal membranes, and related alveolar bone was needed for better evaluation of the probable changes in those tissues as a result of alterations in local circulation. The same surgical operation was performed on six additional monkeys. The monkeys were killed at 1, 5, and 12 days, and three, four, and five weeks after surgery. Some heads were perfused with an aqueous solution of India ink to help in vascular studies. Proper mandibular blocks were cut out and histolog. ically processed. Final serial sections were treated with hematoxylin and eosin and Mallory stains.

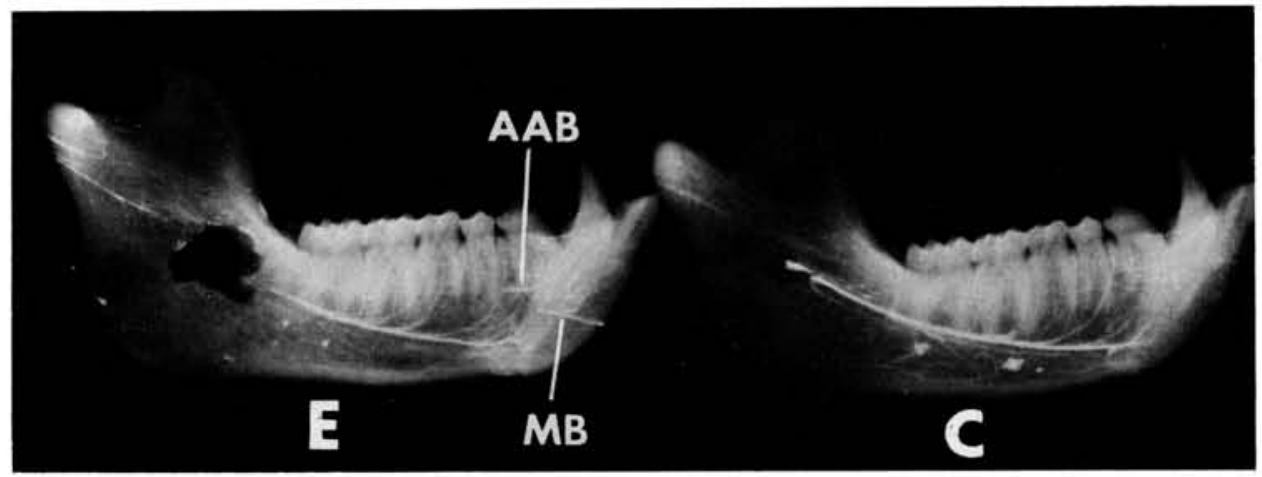

Fig 4.-Angiogram, five days after surgery. Mandibular branch $(M B)$ traversing mandibular symphysis. $A A B$, arterial anastomotic bridges; $E$, experimental side; $C$, control side. 


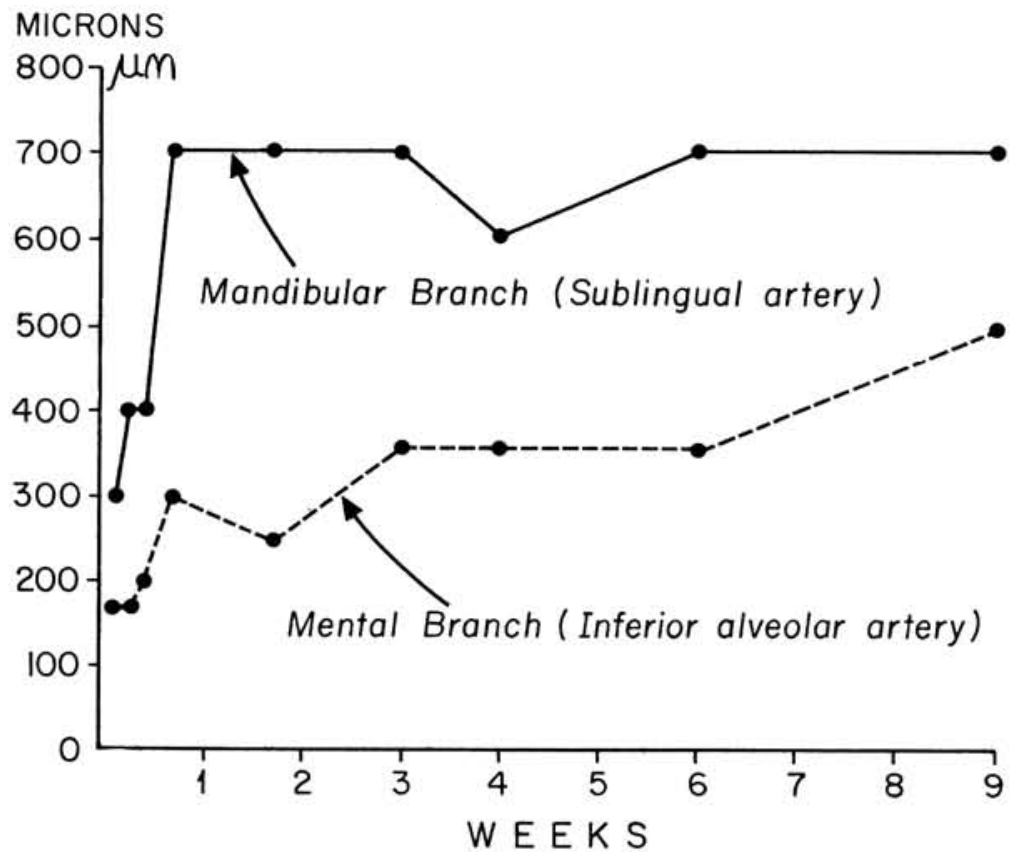

FIG 5.-Relative growth of mental branch as compared with mandibular branch after circulation through inferior alveolar artery was interrupted. Measurements taken from specimens and angiograms. $\mu \mathrm{m}$, micrometers.

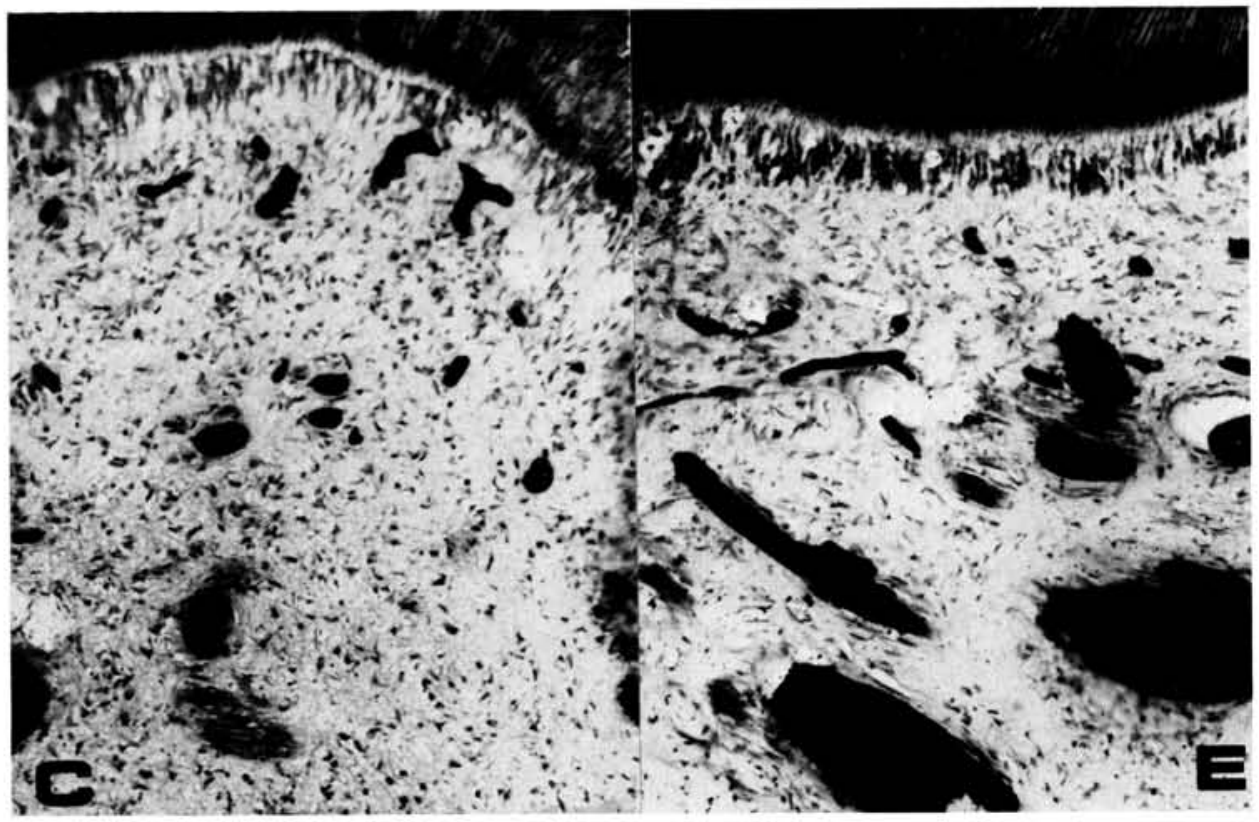

FIG 6.-One day after surgery. On experimental side $(E)$, shrinkage of fibrocytes as well as shrinkage and grouping of odontoblasts occurred in dental pulp of second molar. $C$, control side $(\mathrm{mag} \times 125)$. 


\section{Results}

Angiogram Findings.-Angiograms of specimens obtained one, two, three, and five days after surgery revealed that a retrograde blood flow through the inferior alveolar artery had been established. However, the degree of repletion of the artery and its branches, judged by the intensity of their radiolucent images, was variable and not homogenous. A schematic drawing of the newly established retrograde circulation is presented in Figure 1. In the specimen obtained one day after surgery, very tenuous alveolodental branches were noticeable only at the premolar area of the mandibular body. At the molar area, however, these branches were unremarkable (Fig 2). Two days after surgery, a full retrograde blood flow had been established and distinct arterial anastomotic bridges were demonstrable on the angiograms. Anastomotic bridges shunted blood from the mandibular branch of the sublingual artery and into the inferior alveolar artery and its branches (Fig 3 ). Five days postoperatively there was also a good retrograde blood flow through the inferior alveolar artery and the patency of the arterial anastomotic bridges was evident on the angiogram (Fig 4). In all other spec- imens from monkeys killed up to the ninth month postoperatively, there was radiographic evidence of the existence of a wellestablished retrograde blood flow as well as definite, functioning arterial anastomotic bridges.

The degree of participation of the mandibular branch of the sublingual artery and the mental branch in originating and maintaining the retrograde blood flow through the inferior alveolar artery is explained in Figure 5. During the first five days of the experiment there was a consistent increase, from 300 to 700 micrometers $(\mu \mathrm{m})$, in the external diameter of the mandibular branch. In all other specimens studied up to the ninth week, little increase occurred. The external diameter of the mental branch showed a slower but progressive increase throughout the experimental period. Twenty-four hours after surgery, it increased from $170 \mu \mathrm{m}$ to more than $500 \mu \mathrm{m}$ by the ninth postoperative week.

Histopathologic Findings.-No histopathologic changes were found in dental or dental supporting tissues at the premolar area of the experimental mandibular bodies. The pulp tissue of molars, however, showed the following regressive changes: In the

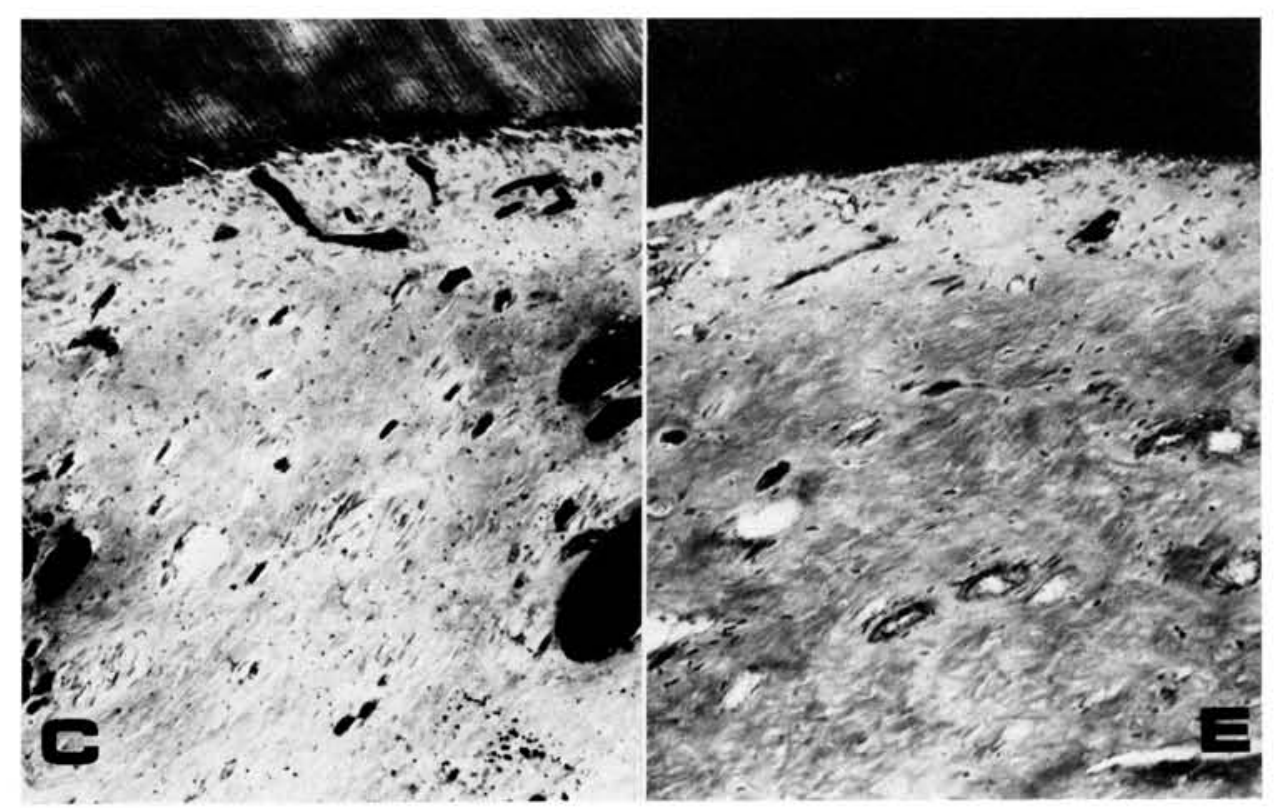

FIG 7.-Five days after surgery. Decrease in number of odontoblasts and fibrocytes occurred on experimental side $(E)$ as compared with control $(C)(\mathrm{mag} \times 125)$. 


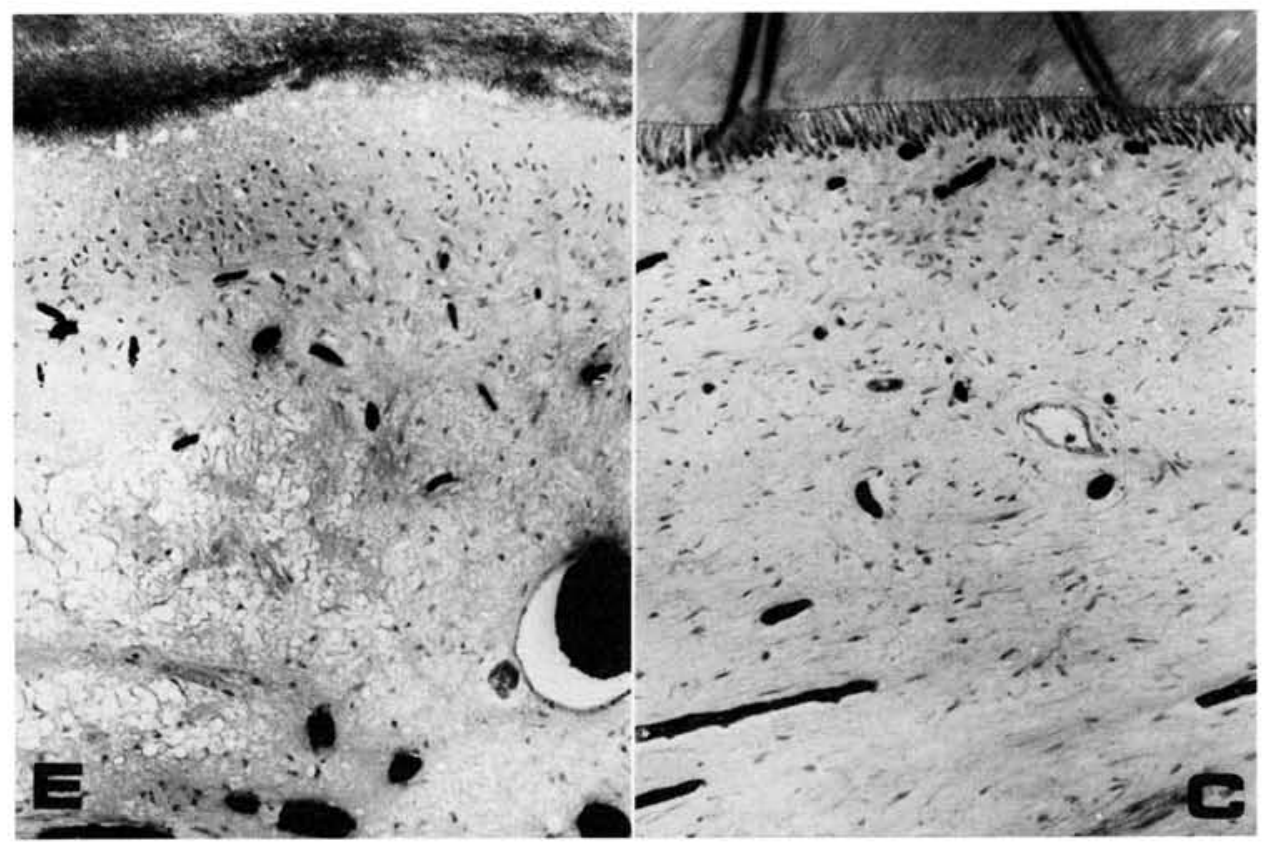

Fig 8.-Twelve days after surgery. Vacuolar degeneration on central part of pulp tissue with severe scarcity of fibrocytes. No odontoblasts are present. $E$, experimental side; $C$, control side $(\operatorname{mag} \times 125)$.

specimen obtained one day after surgery, the pulpal connective tissue showed chromatic changes in the collagenous bundles as well as shrinkage of the fibrocytes. This was in clear contrast to control sides where the cells were big, well-stained, and distributed homogenously. A slight shrinkage and grouping of the odontoblasts occurred (Fig 6). No histopathologic changes were found in the periodontium, alveolar bone, or gingival tissue in this specimen. In the specimen obtained five days after surgery, the pulp tissue showed a decrease in the number of fibrocytes when compared with the control. The odontoblastic layer could not be visualized as such, but only occasional odontoblast cells were present (Fig 7). In the specimen obtained 12 days after surgery, the pulp tissue exhibited a vacuolar degeneration at the midpoint of the pulp with lack of or severe scarcity of fibrocytes. There was a preservation of fibrocytes in areas of the pulp close to the odontoblastic layer. Apparently, no odontoblasts were present, and on the central part of the pulp there were some plasmacytoid lymphocytes (Fig 8). In the specimen obtained three weeks after surgery, there was a complete regeneration of the odontoblasts with a repopulation of the fibrocytes throughout the pulp tissue. There was no evidence of bacteria or inflammatory cell proliferation. The dentin adjacent to the pulp tissue showed focal areas of hyperplasia (Fig 9). In the specimens obtained four and five weeks after surgery, there was a generalized hyperhemic reaction in the pulp tissue. The five-week specimen showed focal hyperplasia of the odontoblasts with a secondary inflammatory reaction that contained mainly lymphocytes and plasma cells. In other fields, there was evidence of vacuolar degeneration of the odontoblast cells.

A hyperhemic reaction was present in all experimental pulps studied but not in the 24-hour specimen where the blood vessels were injected heavily with India ink.

\section{Discussion}

The participation of the mandibular branch of the sublingual artery in originating and maintaining a rapid backflow of blood through the obliterated inferior alveolar artery appeared to be decisive in sus- 
taining the basic nutritional needs of the mandibular body and in preventing bone infarction. There was a need for a fast restitution of the nutritional circulation to the ischemic hemimandibles immediately after the artery was cauterized, and this might have triggered the reacting vasodilating mechanism that involved mainly the mandibular and mental branches and the arterial anastomotic bridges.

Several factors have been considered to explain a vasodilating response. Lewis ${ }^{12}$ and Hilton ${ }^{13}$ stated that when circulation to an organ is cut, there will be an accumulation of intermediary metabolites and the release of a large number of vasoactive substances from active metabolizing cells that would provoke a vasodilating effect on regional blood vessels. Neural14,15 and intrinsic myogenic factors ${ }^{16}$ also are thought to influence the development of collateral circulation and vasodilating effects. In the mandible there appears to be a dual mechanism controlling the vasomotor activity of blood vessels, namely the periarterial sympathetic plexus on the inferior alveolar artery and, according to Mathews et al,17 the inferior alveolar nerve as an additional pathway for vasomotor control. In our specimens, the cauterization of the inferior alveolar artery destroyed the periarterial sympathetic plexus and damaged the inferior alveolar nerve.

The progressive increase in growth shown by the mental branch in all experimental specimens indicates that the normal nutritional needs of the mandibular bodies were still not met by the ninth week after surgery. This is in agreement with Liebow's statement that the blood flow to an organ or tissue by way of collateral vessels is generally inadequate to maintain an acceptable perfusion of the tissue and rarely exceeds the needs of the tissue. 18

A practical consideration emanates from the participation of the mental artery and mandibular branch of the sublingual artery in supporting the retrograde blood flow in the mandible. The preservation of these vessels would be important in mandibular surgery, especially when the blood flow through the inferior alveolar artery has been interrupted. These vessels will provide prompt collateral circulation, maintain the viability of the bone, and accelerate the healing process.

The regressive changes that occurred in

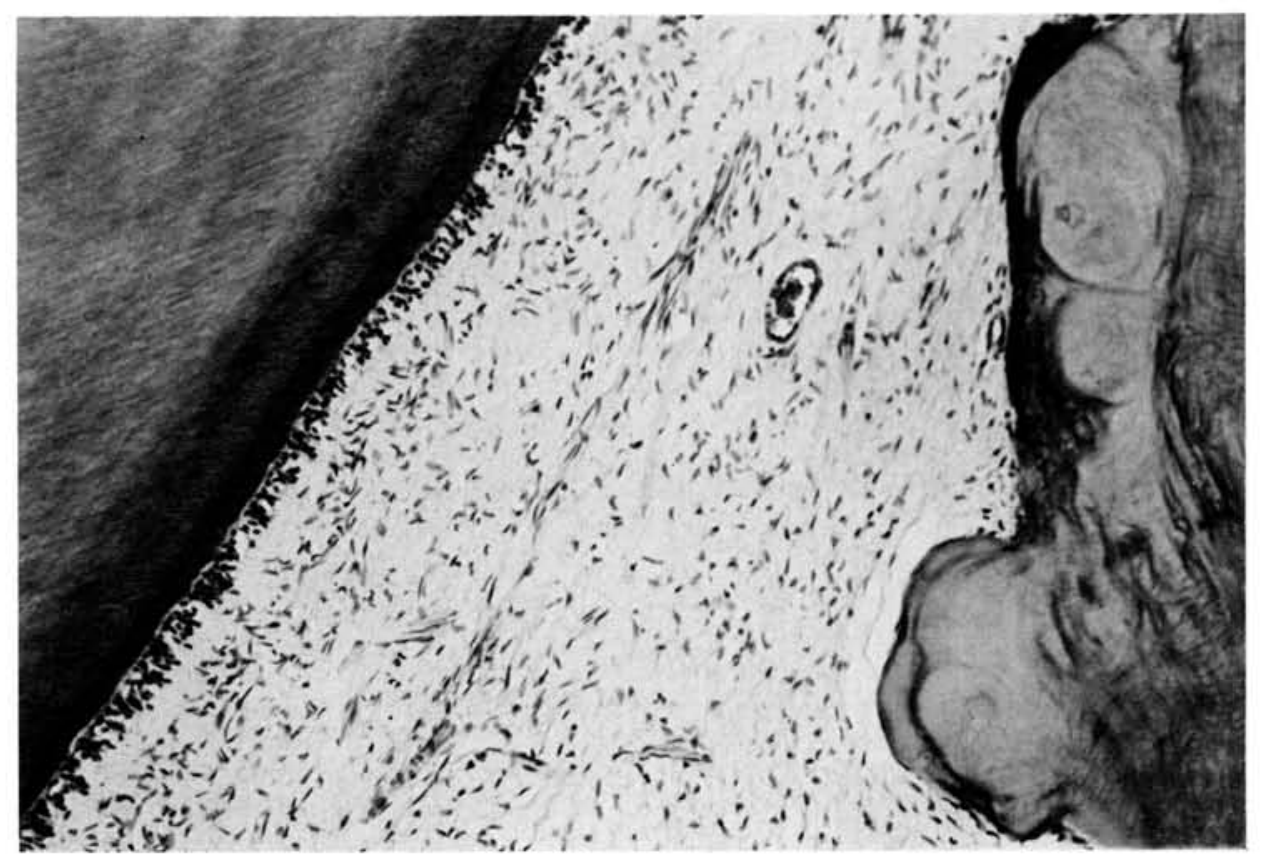

FIG 9.-Three weeks after surgery. Complete regeneration of odontoblasts and repopulation of fibrocytes $(\mathrm{mag} \times 125)$. 
the dental pulps of molars in the experimental hemimandible appeared to be of a nutritional nature and certainly were caused by disturbances in the hemodynamics of the local blood flow. Since the dental pulps of molars were the most distally located tissue to be nourished by the newly established retrograde blood flow, it is probable that the amount of blood and nutrients reaching that area was not sufficient and that a condition of anoxia might have developed. Indeed, most of the odontoblasts probably suffered an irreversible process of coagulation necrosis that ended with the proteolytic digestion of the cells. ${ }^{19}$ But, on the other hand, the regenerative capacity of the pulp tissue was indicated by the connective tissue cells which by a process of cytodifferentiation permitted the repopulation of the odontoblast cells three, four, and five weeks after surgery.

\section{Conclusions}

Collateral circulation through both the mandibular branch of the sublingual artery and the mental branch was the main source of nutrition to the mandibular body immediately after the inferior alveolar artery was cauterized. The progressive and maintained increase in growth shown by the mental branch in all experimental specimens indicates that the collateral circulation created by the time the experiment was over was not sufficient to feed the mandibular bodies properly. The odontoblast cells in the pulp tissue of molars suffered the most regressive changes after the circulation through the inferior alveolar artery was interrupted.

\section{References}

1. Skopakof, S.M.: Etudes morphologiques et expérimentales sur l'apport sanguin a la machoire, Rev Odonto stomatol 16: 50-69, 1958.

2. Stenström, S.J.: New Technique for Intraoral. Ramisection of the Mandible, Plast Re. constr Surg 43: 135-149, 1969.

3. Converse, J.M., and Horowitz, S.L.: The Surgical-Orthodontic Approach to the Treatment of Dentofacial Deformities, $A m J$ Orthod 55: 217-243, 1969.

4. TномA, K.H.: Oblique Osteotomy of the
Mandibular Ramus: Especial Techniques for Correction of Various Types of Facial Deformity and Malocclusion, Oral Surg 14: 23-46, 1961.

5. DeChamplain, R.W.: Mandibular Reconstruction, J Oral Surg 31: 448-462, 1973.

6. CLINE, H.L.: Reconstructive Surgery for Facial Defects, Eye Ear Nose Throat Mon 46: 1524-1531, 1967.

7. Schwartz, D.J., and Hurlke, D.F.: The Morphology of the Head and Neck of the Macaca Monkey, J Dent Res 42: 1222-1233, 1963.

8. CAstelli, W.A.: Vascular Architecture of the Human Adult Mandible, $J$ Dent Res 42: 786.792, 1963.

9. Castelli, W.A., and Huelke, D.F.: The Arterial System of the Head and Neck of the Rhesus Monkey with Emphasis on the External Carotid System, Am J Anat 116: 149$170,1965$.

10. Reiner, L.; Rodriquez, F.L.; and Jimenez, F.A.: An Injection Mass of Maximal Radiopacity for Postmortem Angiography, $J$ Mount Sinai Hospital 24: 1139-1145, 1957.

11. Grayson, J., and Irvine, M.: Myocardial Infarction in the Monkey: Studies on the Collateral Circulation After Acute Coronary Occlusion, Cardiovasc Res 2: 170-178, 1968.

12. Lewis, T.: The Adjustment of Blood Flow to the Affected Limb in Arteriovenous Fistula, Clin Sci 4: 277-285, 1939-1942.

13. Hilton, S.M.: Local Chemical Factors Involved in Vascular Control, Angiologica 8: 174-186, 1971.

14. LIEBow, A.A.: Situations Which Lead to Changes in Vascular Patterns, in Hamilton, W.F. (ed) : Circulation-Handbook of Physiology, Baltimore: Williams \& Wilkins Co., 1963, p 1262.

15. LONGLAND, C.J.: The Collateral Circulation of the Limb, Ann $R$ Coll Surg Engl 13: 16I$176,1953$.

16. Fotkow, B.: Role of the Nervous System in the Control of Vascular Tone, Circulation 21: 760-768, 1960 .

17. Mathews, J.L.; Bishop, J.G.; Moore, E.E.; and DoRman, H.L.: Blood Flow and Blood Pressure Responses to Mandibular Nerve Blocking Agents, J Dent Res 38: 276-280, 1959.

18. LIEBow, A.A.: Situations which Lead to Changes in Vascular Patterns, in Hamilton, W.F. (ed) : Circulation-Handbook of Physiology, Baltimore: Williams \& Wilkins Co., I963, p 1268.

19. RobBins, L.S.: Pathology, Philadelphia: W. B. Saunders Co., 1967, p 22. 